\title{
The neural crest: understanding stem cell function in development and
} disease

\author{
Fuchs, Sebastian ; Sommer, Lukas
}

\begin{abstract}
Complex organs like the nervous system are composed of different cell types which are all derived from multipotent stem cells. In vertebrates, a transient population of stem cells, the neural crest, generates the entire peripheral nervous system as well as non-neural progeny. The developmental processes of cellular differentiation and proliferation require precise coordination and control. Errors in the programs that regulate stem cell function can lead to defects that manifest in developmental disorders, in some cases they might even induce cancer. It is therefore of fundamental interest to understand the mechanisms of stem cell maintenance and differentiation. Using the neural crest as a model system helps us not only to understand the role of stem cells in development but might also lead to new aspects for the cure of stem cell-related diseases.
\end{abstract}

DOI: https://doi.org/10.1159/000100354

Posted at the Zurich Open Repository and Archive, University of Zurich ZORA URL: https://doi.org/10.5167/uzh-115997

Journal Article

Published Version

Originally published at:

Fuchs, Sebastian; Sommer, Lukas (2007). The neural crest: understanding stem cell function in development and disease. Neurodegenerative Diseases, 4(1):6-12.

DOI: https://doi.org/10.1159/000100354 


\title{
The Neural Crest: Understanding Stem Cell Function in Development and Disease
}

\author{
Sebastian Fuchs Lukas Sommer \\ Institute of Cell Biology, Department of Biology, ETH Zurich, Zurich, Switzerland
}

\section{Key Words}

Neural crest $\cdot$ Stem cells $\cdot$ Signaling $\cdot$ Cancer stem cells

\begin{abstract}
Complex organs like the nervous system are composed of different cell types which are all derived from multipotent stem cells. In vertebrates, a transient population of stem cells, the neural crest, generates the entire peripheral nervous system as well as non-neural progeny. The developmental processes of cellular differentiation and proliferation require precise coordination and control. Errors in the programs that regulate stem cell function can lead to defects that manifest in developmental disorders, in some cases they might even induce cancer. It is therefore of fundamental interest to understand the mechanisms of stem cell maintenance and differentiation. Using the neural crest as a model system helps us not only to understand the role of stem cells in development but might also lead to new aspects for the cure of stem cell-related diseases.
\end{abstract}

Copyright $\odot 2007$ S. Karger AG, Basel

\section{Introduction}

Stem cells are the source of all cell types that exist in our bodies. Stem cells are usually defined in terms of two characteristics: first, the ability to produce several types of differentiated progeny (multipotency) and second, the property of self-renewal, meaning that cell division of a stem cell leads again to at least one new stem cell. Not surprisingly, as more has become known about how stem cells function, their therapeutic potential has been envisaged and stem cells have become a research field of major interest. Still, in order to use stem cells as a source for tissue repair and cell replacement therapies we first need to understand in detail how they fulfill their extraordinary functions. Clearly, the processes of differentiation and self-renewal require tight coordination and regulation. Hence, the elucidation of the genetic programs that are at the base of stem cell regulation are of fundamental interest. Furthermore, the question arises of what might happen if these regulatory programs undergo fatal errors. Indeed, malformations may occur when stem cells differentiate at the wrong time, in the wrong place or when their ability to differentiate or self-renew is unexpectedly altered in some way. Especially during development this may prove fatal and lead to developmental disorders manifesting in a disease. Moreover, there is increasing evidence that deregulation of stem cells may lead to malignancy and produce aggressive cancers [1].

In order to understand the abilities of stem cells we need appropriate model systems that allow us to tackle our unresolved questions. One of these suitable systems is provided by neural crest stem cells (NCSCs), a migratory population of cells that arises during development from the dorsal neural tube at the time of neural tube closure [2]. Neural crest cells are of ectodermal origin

\section{KARGER}

Fax +4161306 1234

E-Mail karger@karger.ch

www.karger.com (c) 2007 S. Karger AG, Basel

$1660-2854 / 07 / 0041-0006 \$ 23.50 / 0$

Accessible online at:

www.karger.com/ndd
Prof. Lukas Sommer

Institute of Cell Biology, Department of Biology

ETH Zurich

CH-8093 Zurich (Switzerland)

Tel. +41 4463333 49, Fax +41 4463310 69, E-Mail lukas.sommer@cell.biol.ethz.ch 
and only exist in vertebrates. Their appearance in evolution is not fully understood, but because of their significant contribution to the cellular diversity in vertebrates and their unique features some might consider the neural crest as an addition to the three germ layers, ectoderm, mesoderm and endoderm [3]. NCSCs can give rise to both, neural and non-neural structures. For example, most cells of the peripheral nervous system, e.g. sensory neurons in the dorsal root ganglia, sympathetic and parasympathetic neurons of the autonomic nervous system, chromaffin cells of the adrenal gland and the enteric nervous system of the gut are all of neural crest origin. Nonneural cells comprise melanocytes (the pigment cells of the skin), smooth muscle cells of the heart outflow tract and cranial blood vessels and craniofacial bone and cartilage. This large variety of cells that arise from NCSCs makes them a highly interesting source to investigate how cellular diversity is achieved. Several model organisms are commonly used in neural crest research. The most common are zebra fish, chicken, rat and mouse, while quail-chick chimeras have been proven useful for cell grafting experiments [4-6]. The development of in vitro systems, such as for example neural tube explant cultures, that allow the cultivation of pure NCSC populations, significantly contributed to the field of stem cell research [7]. Altogether, the neural crest serves as a valuable model system for a range of developmental processes, including induction, specification and differentiation, as well as guided cell migration and epithelial-to-mesenchymal transition $[8,9]$.

In the following we will summarize current knowledge regarding some of the factors that regulate NCSCs, findings that may be fundamental on the way to therapeutic applications of stem cells. We will approach the link between the neural crest and certain diseases, showing the molecular and cellular events that may lead to a specific disease. Finally we will evaluate current knowledge concerning neural crest-derived tumors, whether NCSCs might be at the origin of certain cancers, and how this might suggest new ideas for cancer therapies.

\section{Factors Regulating NCSCs}

Neural crest cells arise at the border of neural plate and epidermis at the time of neural tube closure [8]. Following the folding process and neural tube closure neural crest precursors are localized in the dorsal part of the neural tube. There they undergo an epithelial-to-mesenchymal transition and detach from the neural tube in a process called delamination. They acquire unique features that distinguish them from their tissue of origin and begin to migrate extensively throughout the embryo. Significant progress has been made in identifying the mechanisms leading to the induction and specification of the neural crest. We will only outline the factors involved in these steps and refer the interested reader to already existing reviews that give more detailed information $[8$, $10]$.

One of the early inductive signals, BMP4, is expressed in the border region of the epidermis and the neural plate. It was shown that BMP has a dose-dependent effect during neural crest induction. Indeed, high levels of BMP give rise to epidermis, intermediate levels to neural crest and low levels to neural tissue [8]. In addition to BMP, the WNT signaling pathway plays a major role in neural crest induction. Gain and loss of function experiments with members of the WNT signaling pathway have established a requirement for WNT signaling in the induction of the neural crest [11-13]. The actions of early inducing signals trigger the activation of transcription factors in the prospective neural crest leading to further specification. Among these are AP-2, FOXD3, SLUG and SNAIL, c-MYC, RHOB, ZIC-family and SOXE transcription factors (SOX8, SOX9 and SOX10) $[9,10]$.

Interestingly some of the factors that act during early neural crest induction and specification will later on play a role in cell fate decisions of the neural crest. SOX9 seems to be required during early neural crest formation, is down-regulated in migratory NCSCs, but is again expressed in neural crest progenitors that form craniofacial structures $[14,15]$. The same is true for canonical WNT signaling and the BMP pathway. While both have an 'early' role in neural crest induction, they will at a later timepoint have instructive roles in cell fate specification of multipotent neural crest cells, as we will see in the following paragraph.

Following delamination neural crest cells migrate via defined pathways to various locations to contribute to diverse tissues. During and after migration they undergo specific differentiation steps which are influenced by environmental signals (fig. 1). Again BMP signaling plays an important role. More precisely, BMP2 acts as a growth factor and instructs NCSCs to become autonomic neurons of the peripheral nervous system [16]. In addition, canonical WNT signaling acts instructively to promote sensory neurogenesis from NCSCs $[17,18]$. The role of canonical WNT signaling in cell fate specification of neural crest cells contrasts with its known function in stem cells from other tissues: in embryonic, intestinal, 
skin and hematopoietic stem cells, WNTs mainly regulate proliferation of the respective stem cell pools and do not influence fate specification [19]. This suggests that responsiveness to WNTs depends on cell-intrinsic features and the environmental context. It also clearly separates the behavior of NCSCs in the presence of WNT signaling from that of other types of stem cells. Interestingly, the simultaneous action of WNT and BMP signaling on NCSCs does not induce one particular cell fate, but rather keeps these cells in a nondifferentiated multipotent state [20]. Other instructive factors that are involved in neural crest differentiation are glial growth factor neuregulin (NRG), which is required for peripheral gliogenesis and transforming growth factor- $\beta$ (TGF$\beta)$ signaling, which induces non-neuronal fates, for example smooth muscle cells [2].

The transcription factor SOX10, a member of the SRYrelated high mobility group (HMG) of proteins, fulfills a dual role in the neural crest. During the early phase of migration SOX10 is expressed in all NCSCs, whereas later its expression is mainly restricted to cells of the glial lineage [21]. In addition to its role in gliogenesis, studies have demonstrated a requirement for SOX10 to maintain multipotency of migratory and postmigratory NCSCs. SOX10 keeps NCSCs responsive to instructive growth factors that induce different cell lineages [22, 23]. Furthermore, lack of SOX10 leads to increased apoptosis in undifferentiated postmigratory neural crest cells [22].

It may appear surprising that a relatively small number of signaling molecules are sufficient to control the diverse phenomena of stem cell maintenance and their fate decisions. Possibly combinations of these signals have synergistic or antagonistic effects on one another, creating a network of possible inputs on stem cells. Cellular response to these signals may further depend on the local environment of the cell, where the extracellular matrix and neighboring cells influence the cellular interpretation of instructive signals.

\section{Neural Crest in Human Congenital Diseases}

With the neural crest contributing to a variety of tissues and organs it is not surprising that it is also of clinical relevance. In fact, developmental abnormalities of the neural crest are implicated in several congenital diseases, called neurocristopathies. These may be caused by mutations that affect NCSC function. Such links between molecular events of stem cell regulation and disease are of particular interest as they may serve to better understand

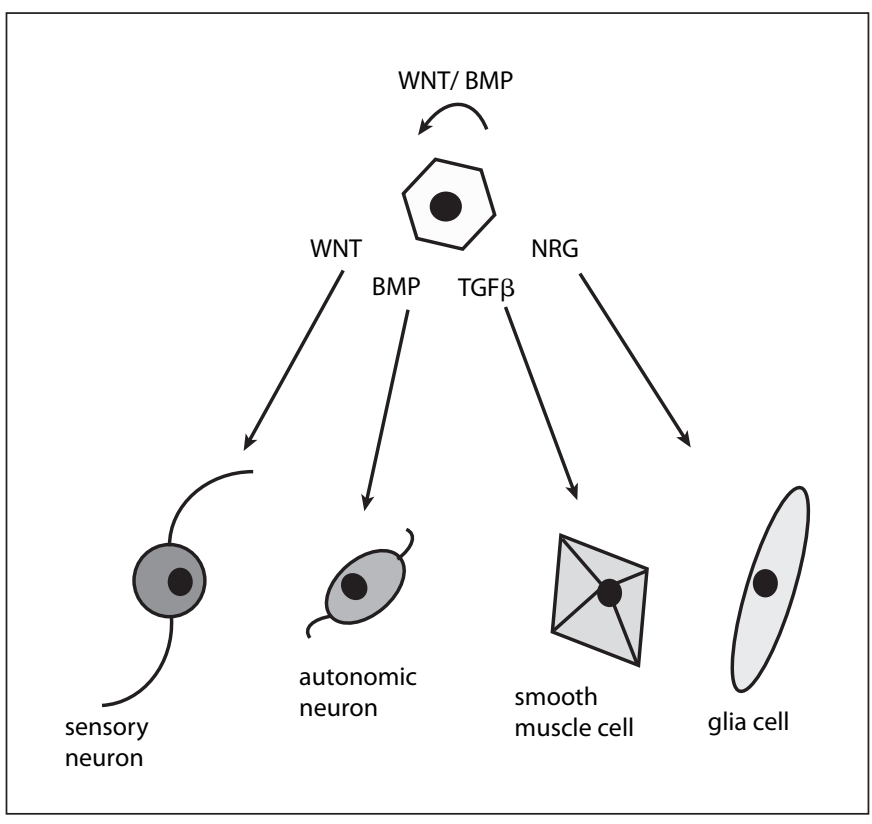

Fig. 1. NCSC response to instructive signals. The combination of WNT and BMP signaling maintains NCSCs in a multipotent state. WNT signaling alone instructs NCSCs to induce sensory neurogenesis and BMP signaling alone induces autonomic neurogenesis. Glial differentiation is induced by NRG, while nonneural differentiation, i.e. into smooth muscle cells, requires TGF- $\beta$ signaling.

both developmental regulation and disease mechanism. One good example is Hirschsprung's disease (HSCR), also called aganglionic megacolon, a relatively common neurocristopathy affecting the enteric nervous system. Patients with HSCR show absence of enteric ganglia (agangliosis) along a variable length of the intestine, with the distal part of the gut being most often affected. HSCR manifests itself in chronic constipation, as a lack of innervation impairs gut motility and enzyme secretion into the intestinal lumen. In HSCR, enteric progenitor cells (EPCs) fail to completely colonize the gut. Normal EPCs are self-renewing and multipotent, giving rise to diverse neurons and glia of the enteric nervous system, and persist in the adult organism [24-26]. Known causes of incomplete colonization are either premature differentiation or impaired migration of EPCs $[24,27]$. The primary genes affected in HSCR are indeed required for proper EPC development and function. Among these are the receptor-tyrosine kinase (RET), endothelin receptor type B (EDNRB), endothelin 3 (EDN3), glial cell line-derived neurotrophic factor (GDNF), SOX10 and others such as endothelin converting enzyme 1 (ECE1) or smad inter- 
Fig. 2. A simplified model of gut colonization by enteric nervous system precursor cells. A EPCs migrate along the gut in proximal to distal direction. EPCs colonize the entire intestine and differentiate into the cells of the enteric nervous system. B Mutations in important regulatory genes lead to impaired EPC colonization of the gut. As a result, innervation of the gut is incomplete.

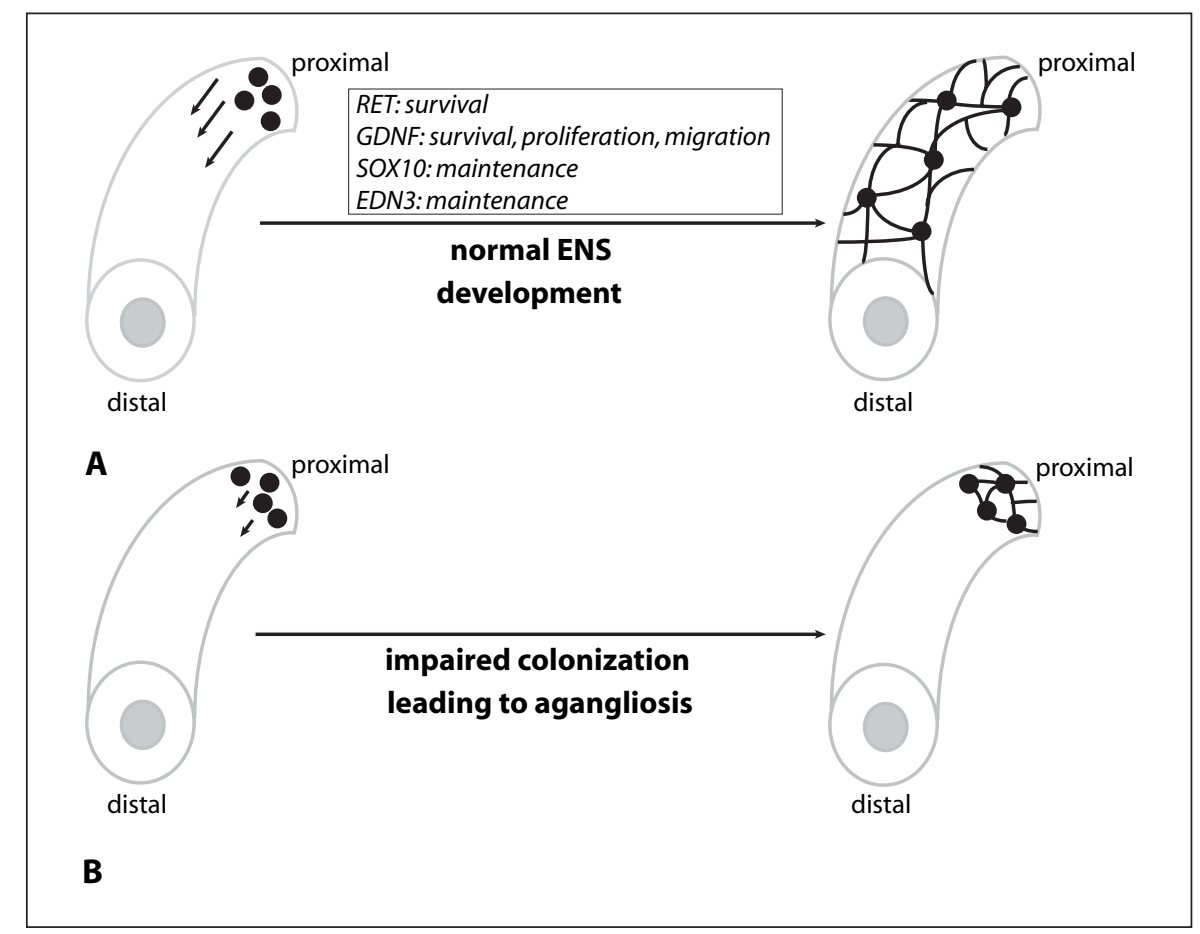

acting protein 1 (SIP1). GDNF acts as a chemoattractant and promotes proliferation and survival of enteric neural crest cells in vitro [28]. The GDNF receptor RET, however, is specifically expressed in EPCs and is necessary for their migration and survival in the gut $[27,29]$. Mutations in RET are among the most common in HSCR patients. EPCs that carry a heterozygous mutation in the transcription factor SOX10 initially show normal migration into the proximal intestine. While their survival capacity remains unaffected, these cells are unable to maintain their progenitor state, leading to premature differentiation and hence to a reduction of the progenitor cell pool size [24]. This depletion then causes incomplete colonization of the more distal gut (fig. 2). Further confirmation comes from a recent study showing that SOX10 overexpression inhibits neuronal and glial differentiation of ENS progenitors without affecting their multipotency [30]. The authors also addressed the function of EDN3 in enteric nervous system development. The data indicates that EDN3 is needed for the maintenance of EPCs. EDN3 is a ligand for EDNRB, a receptor found to be mutated in HSCR patients [31, 32]. Whether the requirement for EDNRB in enteric nervous system development concerns migration or maintenance of enteric precursors has not been clarified so far.
Other neurocristopathies can also affect non-neural derivatives of the neural crest. Promotion of non-neural lineages in NCSCs largely depends on TGF- $\beta$ signaling. Indeed, mice lacking the TGF- $\beta$ type II receptor in neural crest cells show disorders of eye development and additionally display a phenotype resembling DiGeorge syndrome, characterized by anomalies in the development of craniofacial bone and cartilage, the outflow tract of the heart, as well as thymus and parathyroid glands [33, 34].

Taking the example of the enteric nervous system development, it appears that neural crest cells have to integrate a variety of intrinsic and extracellular signals. These processes conceivably involve interactions between distinct factors. Unraveling these interactions between already established and yet unknown regulators will be an important step for the further understanding of developmental and disease mechanisms.

\section{Neural Crest in Cancer}

Tumors are characterized by uncontrolled proliferation of tissue that does not serve a physiological function. They usually show a heterogeneous cellular composition; indeed not all cells within a tumor have the same malig- 
nant potential. This may appear surprising as many tumors have a clonal origin. So what is the origin of this heterogeneity? Recent reports have established the concept of a cancer-initiating cell (or cancer stem cell) that has the potential to initiate and form tumors [35-38]. In analogy to a normal stem cell, such a cancer stem cell can self-renew and undergo multilineage differentiation, giving rise to more benign progeny with limited proliferative potential (fig. 3). While the benign progeny cells compose the major part of the tumor, a relatively small number of proliferative cancer stem cells are sufficient to cause aggressive tumor growth. These findings open up new perspectives for cancer therapies as it might be more efficient to target a specific cell population within a tumor instead of assuming the tumor to be functionally homogeneous. Data on molecular and cellular analysis of tumor biology might need to be reviewed in the light of these findings, as many studies have simply addressed tumors as a single entity. Identification of a specific subset of cells in a tumor requires availability of suitable markers. For example, in the case of medullo- and glioblastomas, aggressive cancers of the central nervous system, the marker CD133 was successfully used to isolate a population of malignant cells with tumor-initiating potential. Moreover these cells showed features reminiscent of neural stem cells [36]. In the case of breast cancer, an epithelial tumor, a fraction of cells expressing CD44 but little or no CD24 (CD44+CD24-/low) showed sustained tumor initiation and growth by serial passaging in a xenotransplantation assay. Furthermore, these cells also generated populations of nontumorigenic cells with different marker expression [35].

The question arises as to where these cancer stem cells originate. Several theories exist, assuming that mutations in somatic stem cells might cause these cells to exit from tight proliferation control. More restricted progenitor or differentiated cells might acquire malignant stem cell properties through mutations. Also, cell fusion events which normally occur in development, e.g. in muscle formation, might be a source of cancer, as fusion events might generate cells with malignant properties [39]. In any case, the influence of the cellular environment should be considered as an additional trigger for the appearance and dissemination of cancer stem cells.

With the extensive contribution of neural crest cells to the vertebrate body, several tumors can be assigned to a neural crest origin. Among these are melanoma, skin tumors which arise from melanocytes, neuroblastoma, a cancer of sympathoadrenal cells and pheochromocytoma, tumors of chromaffin cells of the adrenal medulla or

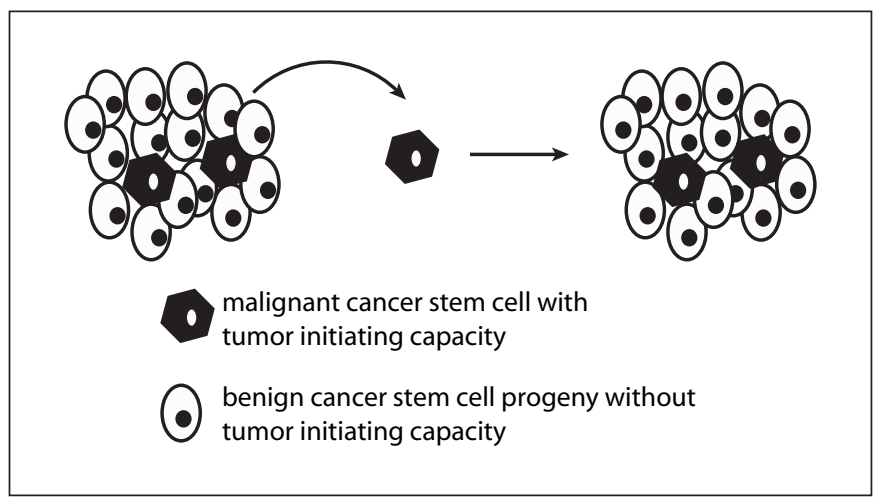

Fig. 3. Tumor initiation and growth can be driven by cancer stem cells. Besides their malignant proliferative potential, these cells are able to self-renew and to give rise to benign progeny cells that represent the major part of the tumor. Benign cancer cells show reduced proliferative potential and are not able to induce tumors de novo.

extra-adrenal paraganglia. Might the concept of tumor appearance through cancer stem cells also apply to neural crest-derived tumors?

In a recent study a subpopulation of cells was found in metastatic melanomas, which could differentiate in vitro into cells reminiscent of some neural crest lineages. These cells might thus have similarities to neural crest stem or progenitor cells, although this has not yet been analyzed [40]. Moreover, upon transplantation of labeled adult human metastatic melanoma cells in ovo into the premigratory neural crest of chicken embryos, melanoma cells distributed along neural crest migratory pathways. They seemed to have lost their tumorigenic potential and partially acquired normal neural crest features. The authors conclude that reprogramming through the embryonic microenvironment occurred [41]. Although this is no proof of any involvement of NCSCs in melanoma formation it is interesting that melanoma cells are able to adopt characteristics of non-pigment neural crest derivatives.

Neuroblastomas are among the most common pediatric tumors. They arise from precursor cells of the neural crest-derived sympathoadrenal lineage. Neuroblastoma is often characterized by an enigmatic clinical behavior: these tumors may regress spontaneously, especially when occurring before 1 year of age. However, aggressive tumor growth and metastatic disease are often observed when neuroblastoma is diagnosed after 1 year of age. It is still unclear whether favorable and unfavorable neuroblastomas arise from a common precursor or if they rather have distinct origins. The occurrence of neuroblasto- 
mas at a rather early time in life suggests that their occurrence and behavior may be linked to developmental programs that are still ongoing after birth and that might involve rather undefined stem or precursor cells of the sympathoadrenal lineage. In agreement with this idea, certain neuroblastoma cell lines contain cells with morphological features and differentiation behavior characteristic of prospective stem cells [42]. Compared to neuroblastoma cell lines without stem cell features, candidate cancer stem cells showed the ability to differentiate, had a growth advantage in vitro and displayed higher tumorigenicity when transplanted into athymic mice [42]. The authors state that these prospective cancer stem cell lines showed expression of CD133 and c-KIT (CD117), markers that are more commonly assigned to hematopoietic (CD133 and c-KIT) and neural stem cells (CD133). In another study the occurrence of a 'side population' (SP) was reported in primary neuroblastomas and cell lines. SP cells are characterized by a high efflux capacity for antimitotic drugs. Interestingly, SP cells from neuroblas- tomas showed the capacity to generate both SP and nonSP cells in vitro, indicating the potential to self-renew and differentiate [43].

It is tempting to speculate that cancer stem cells might be a source for at least some cases of neural crest tumors. To clarify this point it is necessary to better define the cellular composition of neural crest-derived tumors, such as melanomas and neuroblastomas mentioned here. Detailed analysis of relevant marker expression and better functional characterization of tumor cells at a cellular and molecular level should help to understand the etiology of tumorigenesis in neural crest cells. Thus, detailed analysis of the mechanisms regulating NCSC fates during development and disease may be worthwhile goals on the way to establish novel anticancer treatments.

\section{Acknowledgment}

We thank Ned Mantei for critical reading of the manuscript.

\section{References}

1 Pardal R, Clarke MF, Morrison SJ: Applying the principles of stem-cell biology to cancer. Nat Rev Cancer 2003;3:895-902.

2 Le Douarin NM, Dupin E: Multipotentiality of the neural crest. Curr Opin Genet Dev 2003;13:529-536.

3 Hall BK: The neural crest as a fourth germ layer and vertebrates as quadroblastic not triploblastic. Evol Dev 2000;2:3-5.

4 Aybar MJ, Mayor R: Early induction of neural crest cells: lessons learned from frog, fish and chick. Curr Opin Genet Dev 2002;12: 452-458.

5 Le Douarin NM, Ziller C, Couly GF: Patterning of neural crest derivatives in the avian embryo: in vivo and in vitro studies. Dev Biol 1993;159:24-49.

6 Trainor PA: Specification of neural crest cell formation and migration in mouse embryos. Semin Cell Dev Biol 2005;16:683-693.

7 Stemple DL, Anderson DJ: Isolation of a stem cell for neurons and glia from the mammalian neural crest. Cell 1992;71:973-985.

8 Barembaum M, Bronner-Fraser M: Early steps in neural crest specification. Semin Cell Dev Biol 2005;16:642-646.

9 Morales AV, Barbas JA, Nieto MA: How to become neural crest: from segregation to delamination. Semin Cell Dev Biol 2005;16: 655-662.
10 Steventon B, Carmona-Fontaine C, Mayor R: Genetic network during neural crest induction: from cell specification to cell survival. Semin Cell Dev Biol 2005;16:647-654.

11 Garcia-Castro MI, Marcelle C, Bronner-Fraser M: Ectodermal Wnt function as a neural crest inducer. Science 2002;297:848-851.

12 Deardorff MA, Tan C, Saint-Jeannet JP, Klein PS: A role for frizzled 3 in neural crest development. Development 2001;128:36553663.

13 Saint-Jeannet JP, He X, Varmus HE, Dawid IB: Regulation of dorsal fate in the neuraxis by Wnt-1 and Wnt-3a. Proc Natl Acad Sci USA 1997;94:13713-13718.

14 Spokony RF, Aoki Y, Saint-Germain N, Magner-Fink E, Saint-Jeannet JP: The transcription factor Sox 9 is required for cranial neural crest development in Xenopus. Development 2002;129:421-432.

15 Cheung M, Briscoe J: Neural crest development is regulated by the transcription factor Sox9. Development 2003;130:5681-5693.

16 Shah NM, Groves AK, Anderson DJ: Alternative neural crest cell fates are instructively promoted by TGFbeta superfamily members. Cell 1996;85:331-343.

17 Lee HY, Kleber M, Hari L, Brault V, Suter U, Taketo MM, Kemler R, Sommer L: Instructive role of Wnt/beta-catenin in sensory fate specification in neural crest stem cells. Science 2004;303:1020-1023.
18 Hari L, Brault V, Kleber M, Lee HY, Ille F, Leimeroth R, Paratore C, Suter U, Kemler R, Sommer L: Lineage-specific requirements of beta-catenin in neural crest development. J Cell Biol 2002;159:867-880.

19 Kleber M, Sommer L: Wnt signaling and the regulation of stem cell function. Curr Opin Cell Biol 2004; 16:681-687.

20 Kleber M, Lee HY, Wurdak H, Buchstaller J, Riccomagno MM, Ittner LM, Suter U, Epstein DJ, Sommer L: Neural crest stem cell maintenance by combinatorial Wnt and BMP signaling. J Cell Biol 2005;169:309320.

21 Britsch S, Goerich DE, Riethmacher D, Peirano RI, Rossner M, Nave KA, Birchmeier C, Wegner M: The transcription factor Sox 10 is a key regulator of peripheral glial development. Genes Dev 2001;15:66-78.

22 Paratore C, Goerich DE, Suter U, Wegner M, Sommer L: Survival and glial fate acquisition of neural crest cells are regulated by an interplay between the transcription factor Sox 10 and extrinsic combinatorial signaling. Development 2001;128:3949-3961

23 Kim J, Lo L, Dormand E, Anderson DJ: SOX10 maintains multipotency and inhibits neuronal differentiation of neural crest stem cells. Neuron 2003;38:17-31. 
24 Paratore C, Eichenberger C, Suter U, Sommer L: Sox10 haploinsufficiency affects maintenance of progenitor cells in a mouse model of Hirschsprung disease. Hum Mol Genet 2002;11:3075-3085.

25 Kruger GM, Mosher JT, Bixby S, Joseph N, Iwashita T, Morrison SJ: Neural crest stem cells persist in the adult gut but undergo changes in self-renewal, neuronal subtype potential, and factor responsiveness. Neuron 2002;35:657-669.

26 Bixby S, Kruger GM, Mosher JT, Joseph NM, Morrison SJ: Cell-intrinsic differences between stem cells from different regions of the peripheral nervous system regulate the generation of neural diversity. Neuron 2002;35: 643-656.

27 Taraviras S, Marcos-Gutierrez CV, Durbec P, Jani H, Grigoriou M, Sukumaran M, Wang LC, Hynes M, Raisman G, Pachnis V: Signalling by the RET receptor tyrosine kinase and its role in the development of the mammalian enteric nervous system. Development 1999;126:2785-2797.

28 Heuckeroth RO, Lampe PA, Johnson EM, Milbrandt J: Neurturin and GDNF promote proliferation and survival of enteric neuron and glial progenitors in vitro. Dev Biol 1998; 200:116-129.

29 Iwashita T, Kruger GM, Pardal R, Kiel MJ, Morrison SJ: Hirschsprung disease is linked to defects in neural crest stem cell function. Science 2003;301:972-976.
30 Bondurand N, Natarajan D, Barlow A, Thapar N, Pachnis V: Maintenance of mammalian enteric nervous system progenitors by SOX10 and endothelin 3 signalling. Development 2006;133:2075-2086.

31 Puffenberger EG, Hosoda K, Washington SS Nakao K, deWit D, Yanagisawa M, Chakravarti A: A missense mutation of the endothelin-B receptor gene in multigenic Hirschsprung's disease. Cell 1994;79:1257-1266.

32 Baynash AG, Hosoda K, Giaid A, Richardson JA, Emoto N, Hammer RE, Yanagisawa M: Interaction of endothelin-3 with endothelin$B$ receptor is essential for development of epidermal melanocytes and enteric neurons. Cell 1994;79:1277-1285.

33 Wurdak H, Ittner LM, Lang KS, Leveen P, Suter U, Fischer JA, Karlsson S, Born W, Sommer L: Inactivation of TGFbeta signaling in neural crest stem cells leads to multiple defects reminiscent of DiGeorge syndrome. Genes Dev 2005;19:530-535.

34 Ittner LM, Wurdak $\mathrm{H}$, Schwerdtfeger K, Kunz T, Ille F, Leveen P, Hjalt TA, Suter U, Karlsson S, Hafezi F, Born W, Sommer L: Compound developmental eye disorders following inactivation of TGFbeta signaling in neural-crest stem cells. J Biol 2005;4:11.

35 Al-Hajj M, Wicha MS, Benito-Hernandez A, Morrison SJ, Clarke MF: Prospective identification of tumorigenic breast cancer cells. Proc Natl Acad Sci USA 2003;100:39833988.

36 Singh SK, Hawkins C, Clarke ID, Squire JA, Bayani J, Hide T, Henkelman RM, Cusimano MD, Dirks PB: Identification of human brain tumour initiating cells. Nature 2004;432: 396-401.
37 Bonnet D, Dick JE: Human acute myeloid leukemia is organized as a hierarchy that originates from a primitive hematopoietic cell. Nat Med 1997;3:730-737.

38 Lapidot T, Sirard C, Vormoor J, Murdoch B, Hoang T, Caceres-Cortes J, Minden M, Paterson B, Caligiuri MA, Dick JE: A cell initiating human acute myeloid leukaemia after transplantation into SCID mice. Nature 1994;367:645-648.

39 Bjerkvig R, Tysnes BB, Aboody KS, Najbauer J, Terzis AJ: Opinion: the origin of the cancer stem cell: current controversies and new insights. Nat Rev Cancer 2005;5:899-904.

40 Fang D, Nguyen TK, Leishear K, Finko R, Kulp AN, Hotz S, Van Belle PA, Xu X, Elder DE, Herlyn M: A tumorigenic subpopulation with stem cell properties in melanomas. Cancer Res 2005;65:9328-9337.

41 Kulesa PM, Kasemeier-Kulesa JC, Teddy JM, Margaryan NV, Seftor EA, Seftor RE, Hendrix MJ: Reprogramming metastatic melanoma cells to assume a neural crest cell-like phenotype in an embryonic microenvironment. Proc Natl Acad Sci USA 2006;103: 3752-3757.

42 Walton JD, Kattan DR, Thomas SK, Spengler BA, Guo HF, Biedler JL, Cheung NK, Ross RA: Characteristics of stem cells from human neuroblastoma cell lines and in tumors. Neoplasia 2004;6:838-845.

43 Hirschmann-Jax C, Foster AE, Wulf GG, Nuchtern JG, Jax TW, Gobel U, Goodell MA, Brenner MK: A distinct 'side population' of cells with high drug efflux capacity in human tumor cells. Proc Natl Acad Sci USA 2004;101:14228-14233. 